\title{
Suitability of Containers from Different Sources as Breeding Sites of Aedes aegypti (L.) in a Cemetery of Buenos Aires City, Argentina
}

\author{
Darío Vezzani+ ${ }^{+}$Nicolás Schweigmann
}

Unidad de Ecología de Reservorios y Vectores de Parásitos, Facultad de Ciencias Exactas y Naturales, Universidad de Buenos Aires, Ciudad Universitaria, Pabellón II, $4^{\circ}$ piso, 1428 Buenos Aires, Argentina

Cemeteries are ideal urban areas to study the importance of different types of containers as breeding sites of Aedes aegypti (L.). In the present study, the suitability of plastic, glass, ceramic and metal containers was evaluated in four patches within a cemetery of Buenos Aires City, Argentina. Between October 1998 and May 2000, we found 215 breeding sites of Ae. aegypti out of 13,022 water-filled containers examined. In two patches containing microenvironments sheltered from the sun, the use of the different types of containers was proportional to the offer (correlation coefficient $=0.99, P<0.05$ in both cases). In the remaining patches, plastic and metal containers were the most and less frequent breeding sites, respectively $(P<0.001$ in both cases). The number of immatures per breeding site (median $=4.5$ ) did not show significant differences among the four types of containers examined $\left(H_{3,215}=1.216, P=0.749\right)$. Differences found in patches from a same cemetery suggest that different microenvironmental conditions affect the suitability of each type of container for Ae. aegypti breeding. Plastic containers appeared as key breeding sites that should be removed to reduce the Ae. aegypti population in the study area.

Key words: Aedes aegypti - cemeteries - breeding sites - Buenos Aires - Argentina

Aedes aegypti (Linneo 1762) is one of the most studied culicid species because of its frequent use in experimental research, its presence in houses and its importance as vector of urban yellow fever and dengue (Tinker 1964). However, the ecology of this mosquito remains largely misunderstood (Rodhain 1996) and a more comprehensive knowledge of Ae. aegypti biology is needed to predict and explain dengue outbreaks (Fernandez-Salas \& Flores-Leal 1995). In particular, little information on the ecology of this vector is available at the southern limit of its distribution, namely Buenos Aires, Argentina (Vezzani et al. 2001).

Within the urban environment where Ae. aegypti is found, cemeteries fulfil most of its prime requirements due to the presence of numerous water-filled containers, flowers, few buildings surrounded by vegetation, and permanent sources of human blood (Vezzani et al. 2001). Moreover, the different micro- and macrohabitats present within and among cemeteries provide an opportunity to investigate how environmental factors influence the distribution and abundance of container-inhabiting mosquitoes (O'Meara et al. 1992b). Studies conducted in cemeteries of Florida (O'Meara et al. 1992b), Manila (Schultz 1989), and Caracas (Barrera-R et al. 1979) showed high infestation levels of Ae. aegypti. In Buenos Aires, this mosquito was detected in 4 out of the 5 cemeteries present in the city (Vezzani et al. 2001).

CONICET provided funding for the work.

${ }^{+}$Corresponding author. Fax: +54-11-4373-6102. E-mail: vzztato@fibertel.com.ar; dvzz@hotmail.com

Received 11 January 2002

Accepted 21 March 2002
The preimaginal stages of this mosquito develop in artificial containers of small volume, such as flasks, bottles, and flower vases (Christophers 1960). Some of the factors influencing the selection of containers as Ae. aegypti breeding sites are volume (Tinker 1964, Focks et al. 1981), size of water surface (Gomez \& Levin 1995), purpose for which they are used (Bisset et al. 1985, Kittayapong \& Strickman 1993, Focks \& Chadee 1997), and type of material they are made of (O'Meara et al. 1992a, b, Walker et al. 1996).

The size and volume of cemetery containers are more homogeneous than those found in other urban areas (Barrera-R et al. 1979), and all cemetery containers are used as flower vases. Therefore, cemeteries represent ideal areas to investigate the occurrence of Ae. aegypti in containers made of different materials. In this work, we evaluated the suitability of plastic, glass, ceramic and metal containers as Ae. aegypti breeding sites in a cemetery.

\section{MATERIALS AND METHODS}

Study area - Chacarita, the largest cemetery of Buenos Aires City (72 ha), is administered by municipal authorities. It is located near the geographic centre of the city (Fig. 1), in a crowded neighbourhood of high buildings and intense commercial activity. The cemetery, surrounded by walls about $5 \mathrm{~m}$ high, shows a great variety of environments such as open fields, walls, shady galleries with up to 4 underground levels, and closed mausoleums. The average vegetation cover calculated for the whole cemetery is $26 \%$, ranging from $0 \%$ to $40 \%$ per ha.

Local authorities provide most of the existing containers (black plastic cubes or cones and metal cones); the rest of the containers (ceramic vases, glass flasks and cans of different shapes and sizes) are carried by visitors. All containers are used as flower vases ranging between 0.25 and 21 . 


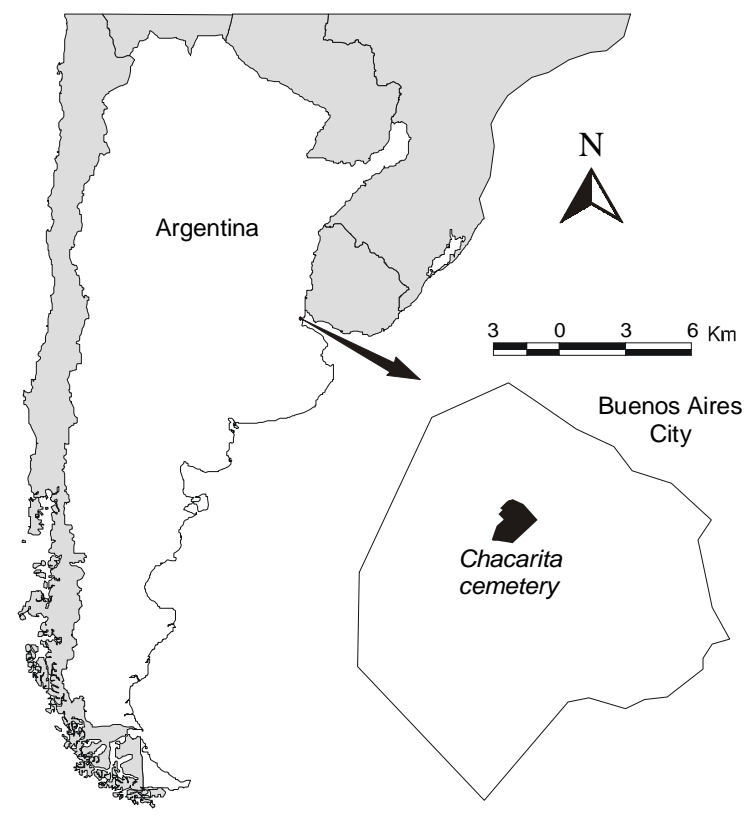

Fig. 1: location of Chacarita cemetery in Buenos Aires City, Argentina

Preliminary study - In September 1998, before the first study period, all containers present in the cemetery were counted. In order to detect areas positive for Ae. aegypti, the monitoring of breeding sites was carried out between October 1998 and May 1999 (mid-spring to mid-autumn). Sampling of containers was made in 40 squares of $50 \times 50$ $\mathrm{m}$ each, which were weekly selected at random from an imaginary grid covering the whole cemetery. The median number of containers examined weekly was 1,166 (first quartile $=1,112$, third quartile $=1,239$ ).

Water-filled and positive containers were recorded. The latter were classified according to their type of material. The water in each container was filtered with a fine mesh strainer and all individuals collected were fixed in $70 \%$ ethanol. A key for mosquitoes of Argentina (Darsie 1985 ) was used in the laboratory to identify immature $A e$. aegypti individuals.

Main work - During the second study period (January-May 2000), the survey was conducted in four patches involving distinct landscapes that had revealed the presence of Ae. aegypti the year before. These environments were as follows: (1) open field, exposed to permanent sunlight and containing microenvironments sheltered from the sun by vegetation; (2) wall 1 , sunlight from midday to sunset and absence of vegetation cover; (3) wall 2, sunlight from dawn to midday and absence of vegetation cover; (4) underground gallery, shade provided by roof and presence of vegetation. In the open field containers were placed on the ground, while in the remaining environments they were arranged in rows one above the other.

All containers present in each patch were counted and classified by type of material. A sampling of 100 randomly selected containers was made weekly in each patch. The number of water-filled containers and those holding immature Ae. aegypti were recorded. Positive containers were classified by type of material.

During both study periods, the number of immature Ae. aegypti (3rd and 4th instar larvae and pupae) found in each container was counted. Flower vases were classified as plastic, ceramic, glass and metal containers. The latter were made of bronze, copper, iron or aluminium. The frequency of occurrence of other mosquito species was not assessed.

Data analysis - The infestation levels of Ae. aegypti were estimated by using the container index (CI): percentage of water-holding containers infested with larvae or pupae (PAHO 1995).

The Pearson product-moment correlation coefficient (Zar 1999) was used to evaluate whether the use of different types of containers was proportional to their offer in each patch.

The relationship between the offer and the number of positive containers found for each type of container was evaluated by means of the test for proportions (Fleiss 1981).

The Kruskal-Wallis test was used to compare the abundance of immature Ae. aegypti among the four types of containers (Sokal \& Rohlf 1969).

\section{RESULTS}

Preliminary study - The cemetery showed a high infestation heterogeneity, from wide areas where no breeding site was found to small patches containing positive vases throughout the study period. The availability of containers in the whole cemetery was 103,596. A total of 98 breeding sites of Ae. aegypti was found in 9,650 waterfilled containers examined $(\mathrm{CI}=1 \%)$.

From the 98 breeding sites recorded, $70.4 \%$ were plastic, $13.3 \%$ ceramic, $9.2 \%$ metal and $7.1 \%$ glass containers. Since the offer of each type of container was not available, the suitability for Ae. aegypti breeding was not assessed during the first study period.

Main work - The Ae. aegypti CI calculated in each of the studied patches were as follows: open field $=4.8 \%$ $(78 / 1,605)$, wall $1=3.1 \%(12 / 388)$, wall $2=2.7 \%(17 / 632)$, gallery $=1.3 \%(10 / 747)$. Out of 117 breeding sites found, plastic containers, once again, showed the highest percentage $(82.1 \%)$, followed by glass $(8.5 \%)$, metal $(6 \%)$ and ceramic $(3.4 \%)$ containers. However, when considering the offer of each type of container per patch (Fig. 2), the use of containers for breeding was proportional to their offer in open fields and gallery (correlation coefficient $=$ 0.99 and $P<0.05$ in both cases). By contrast, in both walls some type of container was used in a higher proportion than the rest (correlation coefficient $=0.40$ and $0.46, P=$ 0.6 and 0.5$)$. Such containers were made of plastic material $(P<0.001)$, while metal containers were the less used in proportion to their offer $(P<0.001)$.

Abundance of immatures - Late instars (3rd and 4th larvae) and pupae of Ae. aegypti were present in the four types of containers. In the 215 positive containers found during the whole study, the median number of individuals per breeding site was 4.5 (first quartile $=2$, third quartile $=$ 11). The median number of individuals did not differ significantly among the four types of containers examined $\left(\mathrm{H}_{3,215}=1.216, P=0.749\right.$; Fig. 3$)$. 


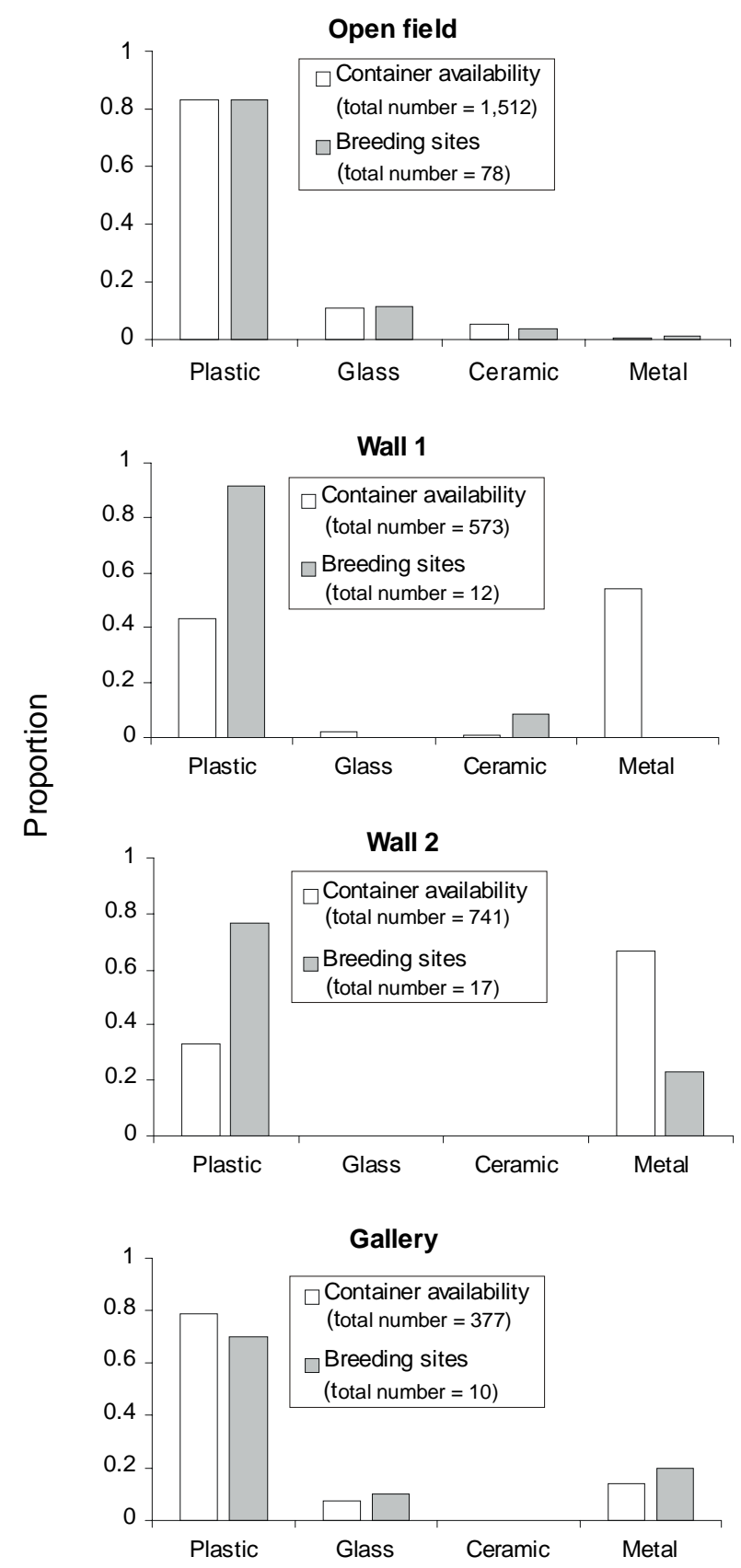

Fig. 2: relationship between the availability of containers and Aedes aegypti breeding sites per patch, according to the four types of containers studied.

Plastic containers accounted for $77 \%$ of all positive containers recorded throughout the study period.

\section{DISCUSSION}

Patches where the use of containers was proportional to the offer included a considerable amount of microenvironments permanently sheltered from sunlight. By contrast, in patches where plastic containers were the most suitable for breeding, all microenvironments were exposed to direct sunlight. Therefore, differences found among

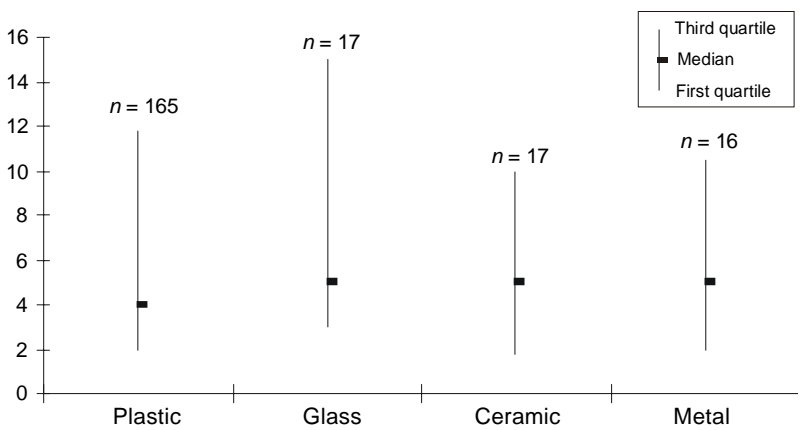

Fig. 3: median number and quartiles of immature Aedes aegypti per type of container.

patches from a same cemetery suggest that microenvironmental conditions affect the suitability of containers as breeding sites of Ae. aegypti.

Although the effect of colour on the suitability of containers was disregarded in our study, approximately $90 \%$ of the plastic containers were black. Black containers are cited as the most attractive coloured target both for male (Fay 1968) and female (Muir et al. 1992) mosquitoes.

Metal containers were the less abundant breeding sites of Ae. aegypti. Studies conducted in a cemetery of Florida (O’Meara et al. 1992a, b, Walker et al. 1996), demonstrated that Aedes larvae were less common in bronze vessels, probably due to the toxicity of copper ions. Other factor to consider is the overheating of water in metal containers. In the study area, water held in these type of containers reached temperatures as high as $45^{\circ} \mathrm{C}$ at midday (unpublished observations), which are lethal for immatures (Fay 1964, Tun Lin et al. 2000). Similarly, the inner surface of metal containers may reach lethal temperatures for eggs (Mulla \& Chaudhury 1968).

Regarding that Ae. aegypti is associated to urban environments, different habits of water use by humans may have an important effect on local vector populations. Shiram and Seghal (1999) found in India that the breeding preference ratio was highest for containers made of mud/ brick/cement, followed by metal and plastic containers. These authors reported that breeding preference was correlated with water storage habits of the residents in the localities surveyed. Likewise, Kittayapong and Strickman (1993) concluded that in Thailand the sources of larvae vary in different communities depending on the local habits of water use, and not on the material of the container. Cemeteries give an opportunity to carry out field studies under similar conditions with respect to anthropic habits of use of water.

Although the mechanisms underlying container suitability are beyond the scope of our study, two distinct components may be involved: (1) the female selection for oviposition, and (2) the impact of the container quality on egg hatching and development of immature mosquitoes. Further studies are needed to determine how the type of container affects each one of those components.

Containers of all sources present in the studied cemetery were found positive for Ae. aegypti, with a compa- 
rable number of individuals per receptacle. Regarding that the plastic type was the most frequently infested, it appears as the key breeding site to be removed in order to reduce the infestation level of the local vector population.

\section{ACKNOWLEDGEMENTS}

To Stella Maris Velazquez for her help with the field work and to Silvia Pietrokovsky for her critical review of the manuscript.

\section{REFERENCES}

Barrera-R R, Machado-Alison CE, Bulla LA 1979. Criaderos, densidad larval y segregación de nicho en tres culicidae urbanos (Culex fatigans Wied., C. corniger Theo, y Aedes aegypti L.) en el cementerio de Caracas. Acta Cient Venezol 30: 418-424.

Bisset Lazcano J, Marquetti M, Gonzales B, Mendizabal ME, Navarro A 1985. La abundancia larval de mosquitos urbanos durante la campaña de erradicación del Aedes aegypti (Linnaeus, 1762) y del dengue en Cuba (1981-82). Rev Cub Med Trop 37: 161-168.

Christophers R 1960. Aedes aegypti (L.), the Yellow Fever Mosquito, Cambridge Univ Press, Cambridge, 739 pp.

Darsie Jr RF 1985. Mosquitoes of Argentina. Part I. Keys for identification of adult females and fourth stage larvae in English and Spanish (Diptera, Culicidae). Mosq Syst 17: 153-253.

Fay RW 1964. The biology and bionomics of Aedes aegypti in the laboratory. Mosq News 24: 300-308.

Fay RW 1968. A trap based on visual responses of adult mosquitoes. Mosq News 28: 1-7.

Fernandez-Salas I, Flores-Leal A 1995. El papel del vector Aedes aegypti en la epidemiología del dengue en México. Salud Publica Mex 37: 45-52.

Fleiss JL 1981. Statistical Methods for Rates and Proportions, John Wiley \& Sons, USA, 255 pp.

Focks DA, Chadee DD 1997. Pupal survey: an epidemiologically significant surveillance method for Aedes aegypti: an example using data from Trinidad. Am J Trop Med Hyg 56: 159-67.

Focks DA, Sackett SR, Bailey DL, Dame DA 1981. Observation on container-breeding mosquitoes in New Orleans, Lousiana, with an estimate of the population density of Aedes aegypti (L.). Am J Trop Med Hyg 30: 1329-1335.

Gomez M, Levin L 1995. Influencia de la extensión del agua sobre la selección del criadero en Aedes aegypti (Diptera: Culicidae). $3^{\circ}$ Congreso Latinoamericano de Ecologia, Mérida, Venezuela, secc. 17, p. 6.

Kittayapong P, Strickman D 1993. Distribution of containerinhabiting Aedes larvae (Diptera: Culicidae) at a dengue focus in Thailand. J Med Entomol 30: 601-606.

Muir LE, Kay BH, Thorne MJ 1992. Aedes aegypti (Diptera: culicidae) Vision: response to stimuli from the optical environment. J Med Entomol 29: 445-450.

Mulla MS, Chaudhury MFB 1968. Influence of some enviromental factors on the viability and hatching of Aedes aegypti (L.) eggs. Mosq News 28: 217-221.

O’Meara G, Evans LJ, Gettman A 1992a. Reduce mosquito production in cemetery vases with copper liners. J Am Mosq Control Assoc 8: 419-420.

O'Meara G, Gettman A, Evans LJ, Scheel F 1992b. Invasion of cemeteries in Florida by Aedes albopictus. J Am Mosq Control Assoc 8: 1-10.

PAHO 1995. Dengue y Dengue Hemorrágico en las Américas: Guías para su Prevención y Control, Organización Panamericana de la Salud, Publ Cient no. 548, 109 pp.

Rodhain F 1996. Ecology of Aedes aegypti in Africa and Asia. Bull Soc Pathol Exot 89: 103-106.

Schultz G 1989. Cemetery vase breeding of dengue vectors in Manila, Republic of the Phillipines. J Am Mosq Control Assoc 5: 508-513.

Shriram AN, Sehgal SC 1999. Aedes aegypti (L) in Port Blair, Andaman and Nicobar islands-distribution and larval ecology. J Commun Dis 31: 185-192.

Sokal RR, Rohlf FJ 1969. Biometry, Freeman and Co., San Francisco, $776 \mathrm{pp}$

Tinker ME 1964. Larval habitat of Aedes aegypti (L.) in the United States. Mosq News 24: 426-432.

Tun-Lin W, Burkot T, Kay B 2000. Effects of temperature and larval diet on development rates and survival of dengue vector Aedes aegypti in north Queensland, Australia. Med Vet Entomol 14: 31-37.

Vezzani D, Velázquez SM, Soto S, Schweigman N 2001. Environmental characteristics of the cemeteries of Buenos Aires City (Argentina) and infestation levels of Aedes aegypti (Diptera: Culicidae). Mem Inst Oswaldo Cruz 96: 467-471.

Walker E, O’Meara G, Morgan W 1996. Bacterial abundance in larval habitats of Aedes albopictus in a Florida cemetery. $J$ Vec Ecol 21: 173-177.

Zar JH 1999. Biostatistical Analysis, Prentice Hall, New Jersey, $663 \mathrm{pp}$. 